\title{
Post-Traumatic Gallbladder Injury in Children: Case Rapport
}

\author{
F. B. Balde, T. Mukengue, I. Oualili, Z. Benmassaoud, K. Khatalla, A. Mahmoudi, Y. Bouabdallah
}

Sidi Mohamed Ben Abdallah University Hassan II University and Hospital Center, Fez, Morocco

Email: fatoumatabinta.balde@usmba.ac.ma

How to cite this paper: Balde, F.B., Mukengue, T., Oualili, I., Benmassaoud, Z., Khatalla, K., Mahmoudi, A. and Bouabdallah, Y. (2020) Post-Traumatic Gallbladder Injury in Children: Case Rapport. Open Journal of Pediatrics, 10, 570-575. https://doi.org/10.4236/ojped.2020.103058

Received: August 8, 2020

Accepted: September 24, 2020

Published: September 27, 2020

Copyright $\odot 2020$ by author(s) and Scientific Research Publishing Inc. This work is licensed under the Creative Commons Attribution International License (CC BY 4.0).

http://creativecommons.org/licenses/by/4.0/

\begin{abstract}
Post-traumatic injuries of the gall bladder are rare. We report through a clinical description of its physio-pathological and evolutionary aspects. A 14-year-old boy was received 48 hours after a stabbing attack. After initial haemorrhage, the patient presented clinical improvement; then a sudden deterioration with vague symptoms and disturbance of the hepatic balance. The abdominal CT scan revealed a perivesicular hematoma with a focus on hepatic contusion. Laparoscopy showed a penetrating sore of the liver, but the exploration was limited by an important inflammation of the digestive tract. The diagnosis of gall bladder perforation was made during the operation. We performed a cholecystectomy by laparotomy. Postoperative evolution was simple, removal of the slides at $\mathrm{D}+4$ and discharged at $\mathrm{D}+7$ postoperative after improvement. At the 6th month, he presented an acute intestinal obstruction on bridles, managed at emergency by open surgery. After one year of follow up, the patient has no symptoms. We note that the vague clinical presentation and the limit of imaging examinations made the early diagnosis of a vesicular perforation a real challenge for the clinician. Cholecystectomy remains the optimal treatment.
\end{abstract}

\section{Keywords}

Gall Bladder, Trauma, Perforation

\section{Introduction}

Lesions of the gallbladder are rare [1]. They are the results of direct hits, shear acceleration/deceleration or more commonly penetrating wounds [2]. The lesion's types are classified as contusion, perforation and avulsions [3]. Diagnosis of vesicular perforation is a challenge for the clinician. There is often a delay in clinical presentation with non-specific symptoms. Diagnostic imaging becomes a 
valuable tool for the rapid identification of gallbladder injury [4]. Although other therapeutic approaches are described, cholecystectomy is the optimal treatment [5].

Our purpose is to present through a clinical description of a post-traumatic gallbladder injury, its physio-pathological and evolutionary aspects.

\section{Case Report}

14-year-old boy: a victim of abdominal trauma following a stabbing attack. Hospitalized initially at a peripheral hospital where he received primary care. It is received 2 days after trauma with normal vitals parameters. Clinically, the examination was marked by a right base-thoracic wound of $3 \mathrm{~cm}$, a distended sensitive abdomen (epigastrium the right hypochondrium and the flanks). An abdominal ultrasound found a hepatic contusion (left lobe) associated with haemoperitoneum, the gallbladder seems normal but it contains echogenic sediment, probably hemobilia (Figure 1). The angio scan showed an abundant haemoperitoneum with a peri vesicular hematoma, and hepatic contusion (segment IV).

He benefited from a biological assessment (Table 1), prophylaxis antibiotic, blood transfusion; clinical biology and radiology monitoring. He was discharged on the 5th day after clinical stabilization. It is readmitted at D +8 of the trauma for haematic fluid with lumps of pus through the para-gastric wound. Biological assessment (Table 1) was performed. Abdominal ultrasound: liver was normal, respect of portal and biliary structures, intraperitoneal effusion with finely echogenic content.

Peritoneal fluid sampling study showed: hematic color with 300,000 red blood cells and 20,000 white blood cells including $77 \%$ PNN, with E. coli to culture. Antibiotic has been adapted to the anti-biogramme.

He benefited from a cystoscopy which revealed a significant inflammation of the digestive tract with the presence of numerous false membranes on the underside limiting the exploration, locating the point of introduction of the knife
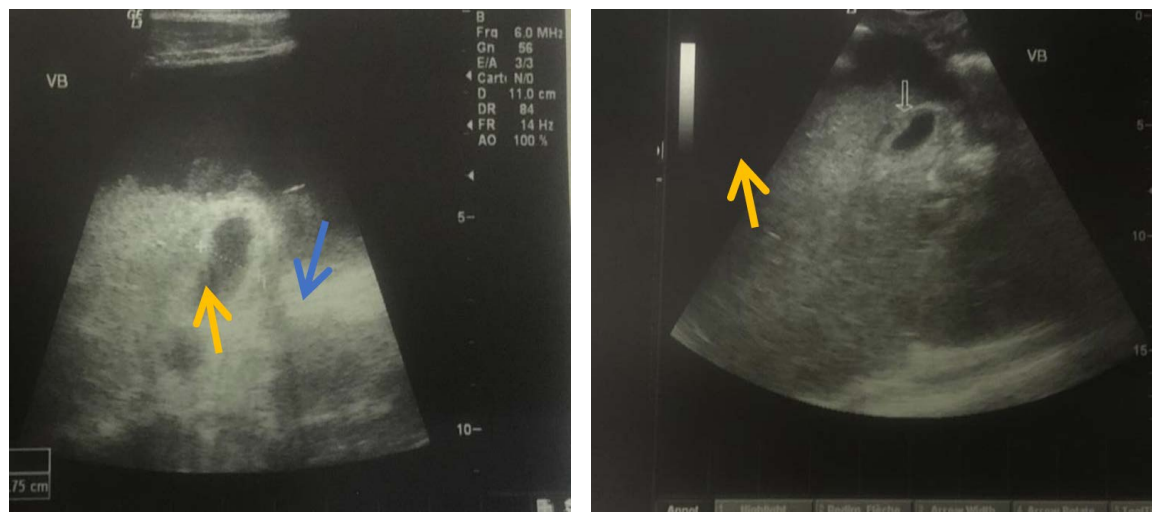

Figure 1. Abdominal ultrasound showing hepatic contusion $(\longrightarrow)$ associated with haemoperitoneum, the gallbladder was normal but it contains echogenic sediment, probably hemobilia $(\longrightarrow)$. 
which sits at the level of the upper face liver. At D +12 , cholecystectomy was performed by laparotomy. We found a compartmentalized pelvic effusion (biliary peritonitis), a significant inflammation of the digestive tract with several adhesions, and a hepatic transvesiculo-cutaneous fistula (Figure 2). The postoperative evolution was simple, removal of the slides at D +4 and discharged at $\mathrm{D}+7$ postoperative after improvement.

At the 6th month, he presented an acute intestinal obstruction on bridles, managed at emergency by open surgery. Release of the flanges is between the 6 th and 9 th intestinal loop.

After one year of follow up, the patient has no symptoms.

\section{Discussion}

Post-traumatic vesicular lesions are rare, accounting for $1.9 \%$ of all abdominal trauma. This rarity is probably related to the protection of the organ by its visceral relations and the rib cage [1] [2] [4]. Often in association with the involvement of other organs including the liver in $83 \%$ to $91 \%$ and $54 \%$ for duodenal and spleen disorders [5].

The clinical presentation and symptoms of gallbladder perforation are monopolized by the associated lesions. Isolated, perforation of the gall bladder is often of delayed presentation with vague symptoms [6]. In many cases, the first symptoms are mild, consisting of abdominal discomfort and diarrhea. Biliary peritonitis may be present initially. A remission period variable is described before sudden deterioration [6]. Oumar Ndour et al. [7] reported the case of a

Table 1. Biological assessment from the day of trauma $(D+0)$ to the exit $(D+23)$.

\begin{tabular}{|c|c|c|c|c|c|c|c|}
\hline & $\mathrm{D}+0$ & $\mathrm{D}+2$ & $\mathrm{D}+5$ & $\mathrm{D}+8$ & $\mathrm{D}+15$ & $\mathrm{D}+18$ & $\mathrm{D}+23$ \\
\hline Hemoglobin (g/dl) & 13 & 8 & 10.5 & 8 & 9.4 & 9.7 & 10 \\
\hline Platelets $10^{\star} 3 / \mathrm{mm}^{3}$ & & 200 & 294 & 600 & 553 & 550 & 527 \\
\hline GOT UI/L & & & 65 & 40 & 25 & 58 & \\
\hline GPT UI/L & & & 22 & 15 & 10 & 27 & \\
\hline $\mathrm{CRP}(\mathrm{mg} / \mathrm{l})$ & & 100 & 200 & 400 & 200 & 108 & 62 \\
\hline
\end{tabular}
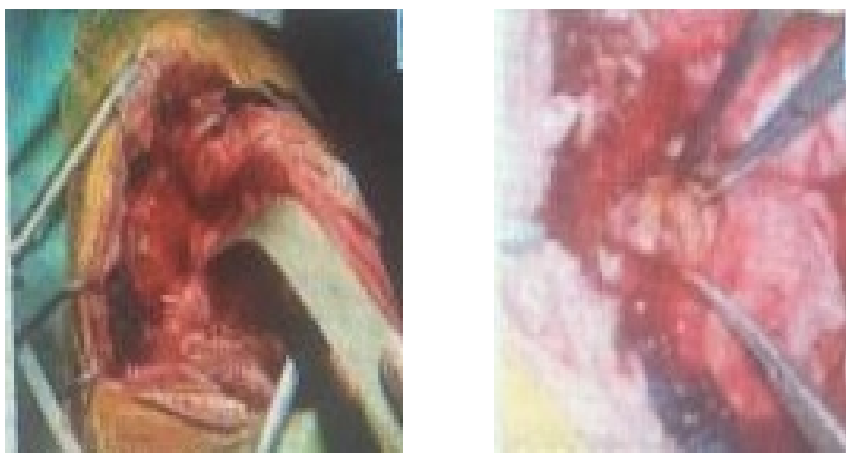

Figure 2. Per-operative images: An hepatic transvesiculo-cutaneous fistula. 
15-year-old adolescent admitted with peritoneal syndrome three weeks after blunt trauma to the abdomen. The diagnosis of vesicular perforation was made by laparotomy.

After a period of hemorrhage our patient presented a good clinical remission before being readmitted 72 hours in clinical and biological deterioration.

Biological analyses are not contributory to either positive diagnosis or differential diagnosis. Sanguine numerous formula will be late in hematoma-related blood spoliation, but useful in monitoring hemorrhage [8].

Disturbances in the hepatic function do not automatically have a direct hepatic lesion significance, but may be indirect in cases of extra-hepatic biliary disease but with hepatic impact [8].

In the traumatic context, observable disturbances have no diagnostic or prognostic value. If we can expect a very disturbed liver assessment in case of serious injury, they do not make the prognosis either. One should not rely on the normality of a liver test in a low suspicion of traumatic hepatic injury to eliminate this lesion; also valid for a lesion of the bile ducts [8].

Our patient was referred for a post-traumatic hemorrhage, clinically stable on examination which justifies our choice to perform a first-line angio-scanner. However, it only identified perivascular hematoma. The diagnosis of perforation was per operative. And according to the classification of Losanoff and Kjossev [9], our patient is classified as type 2 .

Ultrasound is the cornerstone of the initial evaluation of the poly traumatized for the abdominal and thoracic part. The bile ducts are poorly visualizable and one cannot eliminate a biliary lesion by focus assessment ultrasound for trauma, nor even correctly suspect it [10].

CT scan is the reference examination to visualize the heamoperitoneum and the associated hepatic and/or biliary lesion (irregular gallbladder or hematoma in the lumen of the gallbladder). The contusion is probably the most common lesion but the least reported often diagnosed per operative. Perforation is the most commonly reported lesion. Avulsions are the rarest lesions; only eight cases of isolated complete avulsion have been reported [10].

Laparoscopy's main interest is diagnosis, by confirming an heamoperitoneum, a digestive effusion, a diaphragmatic wound, and by allowing to affirm the penetrating character or not of a wound. It avoids an abusive laparotomy in $2 / 3$ of the cases. In the case of a penetrating wound, it will be necessary to be aware of its limits (poor performance for the detection of digestive perforations) and do not hesitate to convert to laparotomy in the case of active bleeding or important peritoneal hematoma masking complete exploration, impossibility to explore the entire digestive tract [11].

In our context, laparoscopy exploration was limited by the abundant peritoneal hematoma but also by an important inflammation of the digestive tract with the presence of numerous false membranes on the inferior surface of the liver.

Perforation of the gallbladder is often treated by laparotomy. The surgeon 
must then look for the involvement of other organs [12]. Cholecystectomy is the optimal treatment [5].

The cholecystorraphy of penetrating lesions has been described, but this procedure presents risks such as a loss of repair and subsequent biliary leakage. In addition, even resorbable sutures placed in the vesicular wall may form a nest for subsequent formation of stones [12].

Cholecystectomy by laparoscopy has been described as the treatment of isolated perforation of the gallbladder due to abdominal injury [13]. However, the laparoscopy approach has certain limitations and is generally not recommended in the case of gallbladder injury, in which other concomitant lesions should be excluded. Although the laparoscope can give a good superficial view of the peritoneal cavity and excellent diaphragmatic view, inspection of the duodenum, pancreas and left hepatitis is not enough in the hands of most general surgeons without experience advanced laparoscopy [13].

\section{Conclusion}

Post-traumatic lesions of the gall bladder are rare, the vague clinical presentation and limited imaging tests in some forms make early diagnosis a real challenge for the clinician. Cholecystectomy remains the optimal treatment despite recent proposals for conservative treatment.

\section{Ethical Aspects}

Parental consent has been obtained for the use of patient's data for possible publication. We have strictly respected confidentiality and anonymity.

\section{Conflict of Interest}

The authors declare that they have no conflict of interest and all authors have read and approved the final document.

\section{References}

[1] Penn, I. (1962) Injuries of the Gallbladder. The British Journal of Surgery, 49, 636-641. https://doi.org/10.1002/bjs.18004921816

[2] Schechter, D.C. (1969) Solitary Wounding of the Gallbladder from Blunt Abdominal Trauma. New York State Journal of Medicine, 69, 2895-2901.

[3] Ball, C.G., Dixon, E., Kirkpatrick, A.W., Sutherland, F.R., Laupland, K.B. and Feliciano, D.V. (2010) A Decade of Experience with Injuries to the Gallbladder. Journal of Trauma Management \& Outcomes, 4, Article No. 3. https://doi.org/10.1186/1752-2897-4-3

[4] Jaggard, M.K.J., Johal, N.S. and Choudhry, M. (2011) Blunt Abdominal Trauma Resulting in Gallbladder Injury: A Review with Emphasis Pediatrics. The Journal of Trauma, 70, 1005-1010. https://doi.org/10.1097/TA.0b013e3181fcfa17

[5] Sharma, O. (1995) Blunt Gallbladder Injuries: Presentation of Twenty-Two Boxes with Review of the Literature. The Journal of Trauma, 39, 576-580. https://doi.org/10.1097/00005373-199509000-00029 
[6] Jaggard, M.K.J., Johal, N., Haddad, M. and Choudhry, M. (2011) Isolated Gallbladder Perforation Following Abdominal Trauma Blunt in a Six-Year-Old Child. Annals, 93, e29-e31.

https://doi.org/10.1308/147870811X580479 https://www.ncbi.nlm.nih.gov/pmc/articles/PMC5827208/pdf/147870811X580479.pdf

[7] Ndour, O., Moustapha, H., Ndoye, N.A. and NGom, G. (2013) Isolated Gallbladder Perforation after Blunt Abdominal Trauma in Children. African Journal of Paediatric Surgery, 10, 41-42. https://doi.org/10.4103/0189-6725.109395

[8] https://thoracotomie.com/2016/11/16/traumatismes-d'foie-et-des-voies-bileaires

[9] Losanoff, J.E. and Kjossev, K.T. (1999) Complete Traumatic Avulsion of the Gallbladder. International Journal of the Care of the Injured, 30, 365-368. https://doi.org/10.1016/S0020-1383(99)00072-8

[10] Pavlidis, T.E., Lalountas, M.A., Psarras, K., Symeonidis, N.G., Tsitlakidis, A., Pavlidis, E.T., et al. (2011) Isolated Complete Avulsion of the Gallbladder (Near Traumatic Cholecystectomy): A Case Report and Review of the Literature. Journal of Medical Case Reports, 5, Article No. 392.

https://doi.org/10.1186/1752-1947-5-392

[11] http://medecine.ups-tlse.fr/dcem4/module11/urgence/201f_abdominal.pdf

[12] Griffiths, E.A., Mohamed, A. and Ball, C.S. (2010) Right Thoracoabdominal Stab Injury Penetrating the Liver and Gallbladder: Case Report and Lessons in Penetrating Knife Wounds to the Chest and Abdomen. BMJ Case Reports, 2010, Article ID: bcr0120102609. https://doi.org/10.1136/bcr.01.2010.2609

[13] Soderstrom, C.A., Maekawa, K., DuPriest Jr., R.W., et al. (1981) Gallbladder Injuries Resulting from Abdominal Trauma Blunt: An Experience and Review. Annals of Surgery, 193, 60-66. https://doi.org/10.1097/00000658-198101000-00010 